\title{
Species-specific patterns of hydraulic lift in co-occurring adult trees and grasses in a sandhill community
}

\section{Oecologia (2004) 138:341-349}

Owing to an unfortunate oversight, corrections were not made to the author's addresses. The correct addresses are given here.
The first sentence of the Abstract should read: Plants can significantly affect ecosystem water balance by hydraulic redistribution (HR) from wet to dry soil layers via roots (also called hydraulic lift, HL, when the redistribution is from deep to shallow soil).

The online version of the original article can be found at http://dx. doi.org/10.1007/s00442-003-1460-8

J. F. Espeleta · J. B. West · L. A. Donovan $(\bowtie)$

Department of Plant Biology, University of Georgia,

Athens, GA 30602, USA

e-mail: donovan@plantbio.uga.edu

Tel.: +1-706-542-2969

Fax: +1-706-542-1805

J. F. Espeleta

La Selva Biological Station, Organization for Tropical Studies,

Puerto Viejo de Sarapiquí,

Heredia, Costa Rica

e-mail: jespele@sloth.ots.ac.cr

J. F. Espeleta

Organization for Tropical Studies Interlink 341,

P.O. Box 02-5635 Miami, FL 33102, USA

J. B. West

Department of Ecology, Evolution and Behavior, University of

Minnesota,

St. Paul, MN 55108, USA

e-mail: westx062@tc.umn.edu 